\title{
Risk of Bone Fracture in Resurfacing Hip Arthroplasty at Varus and Valgus Implant Placements
}

\author{
Nor Aiman Nor Izmin ${ }^{1}$, Fatin Hazwani ${ }^{2}$, Mitsugu Todo ${ }^{3}$, Abdul Halim Abdullah ${ }^{*}$ \\ ${ }^{1}$ Faculty of Mechanical Engineering, Universiti Teknologi MARA (UiTM), 40450 Shah Alam, Selangor, \\ Malaysia \\ 2Interdisciplinary Graduate School of Engineering Sciences, Kyushu University, 6-1 Kasuga-koen, Kasuga 816- \\ 8580, Japan \\ ${ }^{3}$ Research Institute for Applied Mechanics, Kyushu University, 6-1 Kasuga-koen, Kasuga 816-8580, Japan
}

\begin{abstract}
It is possible to have a varus or valgus placement of resurfacing hip implants after resurfacing hip arthroplasty based on clinical reports. The likelihood of accidents such as sideways falls during the recovery process after arthroplasty is higher for the patient due to gait adaptation and weaker lower body condition. Hence, a computational study has been conducted to predict the risk of bone fracture with different implant placements during sideways fall accidents. A CT image of a young adult with hip osteoarthritis was imported into biomechanical software to develop the 3D inhomogeneous femoral bone model. A model of the Birmingham Hip Resurfacing implant with the properties of cobalt-chromium alloy was inserted into the femur during the reconstruction of the arthroplasty, which mimics the procedure of clinical practice. The loading and boundary conditions were implemented to simulate the sideways fall accident, and the prediction of bone fracture was based on the formation of failure elements. The loading magnitude was applied based on the patient's body weight, ranging from the patient's body weight $(1 \mathrm{BW})$ to five times the patient's body weight ( $5 \mathrm{BW})$. The fracture location was predicted to occur at the neck and trochanteric area of the femur, with the greatest damage occurring to the bone model implanted with varus placement. Our finding concludes that the varus placement of the resurfacing hip implant should be avoided whenever possible in clinical practice to sustain bone survivability.
\end{abstract}

Keywords: Bone fracture; Damage formation criterion; Resurfacing hip arthroplasty; Sideways fall; Varus and valgus placement

\section{Introduction}

Resurfacing hip arthroplasty (RHA) is a hip replacement method applied to young adults with end-stage hip osteoarthritis (OA) disease (Isaac et al., 2006; Quesada et al., 2008; Amanatullah et al., 2010; Wagner et al., 2012). Previous studies have discussed the positive surgical outcomes of young adults with hip OA who have undergone RHA (Vail et al., 2006; Mont et al., 2007; Lavigne et al., 2008; Shimmin et al., 2008). Despite that, complications after RHA still exist and have been reported by clinical institutions. Based on the clinical reports, the greatest complication that happens to patients who undergo RHA is bone fracture (Freeman, 1978; Freeman et al., 1978; Shimmin and Back, 2005). Other factors might contribute to the failure, including patient, post-operative, and surgical 
factors, which have been discussed previously (Shimmin and Back, 2005; Sershon et al., 2016).

However, it is believed that the placement of the RHA implant inserted into the femur during the surgical procedure might have a huge impact on the bone condition. Biomechanical factors, such as stress shielding, might also lead to implant loosening and be oriented toward improper placement during the recovery process (Goshulak et al., 2016). Improper placement of the implant might increase the tendency of early bone fracture after arthroplasty.

Since there is a possibility of improper implant placement occurring in RHA, the prediction of bone fracture in emergency cases such as sideways falls might further the understanding of bone failure after RHA. Patients who underwent hip arthroplasty had a higher risk of falling during the recovery process due to gait adaptation and instability (Beaulieu et al., 2010) and might face some difficulties in avoiding environmental hazards (Brunner et al., 2003). The extreme loading exerted on the hip area during a sideways fall can initiate a sudden impact on the area and might lead to the greatest failure, which is bone fracture. Although many CT-FEA studies have discussed the effects of different implant placements after RHA, no study to date has discussed its consequences in the case of an accident. Thus, the current study aims to predict the bone fracture mechanism of intact femurs and femurs that are associated with different RHA implant placements during sideways fall accidents.

\section{Methods}

In this modern era, the combination of computational technology and modern medical tools might produce better and more reliable solutions to biomechanical and biomedical problems. The importance of technology related to biomechanics has been discussed previously (Elfani and Putra, 2013), and various fields, including the medical and health sectors, have agreed with the use of the finite element method (FEM). It is known as one of the most efficient methods, able to reduce costs and time (Kurdi and Rahman, 2010). In modern medicine, a radiation scan is an essential tool to conduct diagnosis and plan future treatment. According to Kim and Jung (2013), the computed tomography (CT) scan is a useful tool in modern medicine, and is also crucial in solving biomedical-related problems. Thus, the combination of CT scans and FEM was applied in this study to predict femoral bone strength with several implant placements after RHA.

\subsection{Development of the Femoral Bone Model}

The femoral bone model developed in this study was based on the CT image of a 47 year-old patient with hip OA disease that occurred on the left femur. The patient had a body weight of $87.6 \mathrm{~kg}$ with a body mass index (BMI) of 30.3. The development of the bone model was conducted using the biomechanics software Mechanical Finder. The inhomogeneous bone model was developed based on the simple linear relationship of the CT value in the Hounsfield unit with the intensity of bone density from the CT image (Todo, 2018; Izmin et al., 2020). Thus, a three-dimensional femoral bone with the distribution of bone mineral density could be generated. The calculation of Young's modulus and yield strength of the bone element was based on previous studies, as shown in Table 1 (Keyak et al., 1997; Keyak et al., 2001; Tawara et al., 2010). Figure 1 shows the variation of bone mineral density (BMD) and Young's modulus of the hip OA patient. 
Table 1 Estimation of young's modulus and yield strength of the inhomogeneous bone model

\begin{tabular}{cc}
\hline Density range & Young modulus \\
\hline$\rho=0$ & $\mathrm{E}=0.001$ \\
$0<\rho \leq 0.27$ & $\mathrm{E}=33900 \rho 2.20$ \\
$0.27<\rho<0.6$ & $\mathrm{E}=5307 \rho+469$ \\
$0.6 \leq \rho$ & $\mathrm{E}=10200 \rho 2.01$ \\
$\rho=0$ & $\mathrm{E}=0.001$ \\
\hline Density range & Yield strength $(\mathrm{MPa})$ \\
\hline$\rho \leq 0.2$ & $\sigma \mathrm{r}=1.0 \times 1020$ \\
$0.2<\rho<0.317$ & $\sigma \mathrm{r}=137 \rho 1.88$ \\
$0.317 \leq \rho$ & $\sigma \mathrm{r}=114 \rho 1.72$ \\
\hline
\end{tabular}
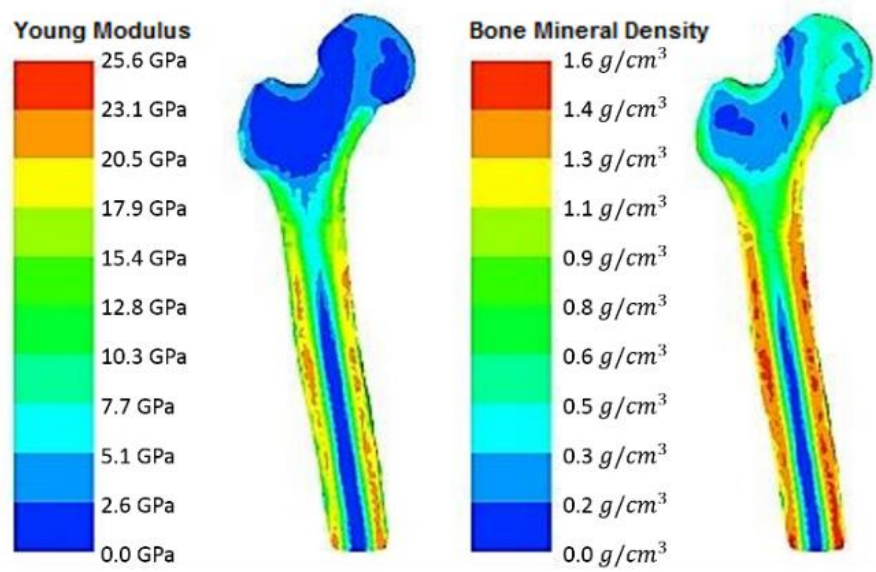

Figure 1 Distribution of young's modulus and BMD of the hip OA patient

\subsection{Properties of the Resurfacing Hip Implant}

The RHA implant model used in this simulation study was based on the properties of the cobalt-chromium alloy ( $\mathrm{CoCr}$ ) with a femoral head size of $50 \mathrm{~mm}$. Table 2 shows the list of properties that have been assigned to the implant model (Abdullah et al., 2017).

Table 2 Properties of Cobalt-Chromium alloys (CoCr)

\begin{tabular}{cccccc}
\hline Material & $\begin{array}{c}\text { Young } \\
\text { modulus } \\
(\mathrm{GPa})\end{array}$ & $\begin{array}{c}\text { Poisson } \\
\text { ratio }\end{array}$ & $\begin{array}{c}\text { Critical stress } \\
(\mathrm{GPa})\end{array}$ & $\begin{array}{c}\text { Yield stress } \\
(\mathrm{GPa})\end{array}$ & $\begin{array}{c}\text { Density } \\
\left(\mathrm{g} / \mathrm{cm}^{3}\right)\end{array}$ \\
\hline RHA Implant & 230 & 0.3 & 0.94 & 2.7 & 8.28 \\
\hline
\end{tabular}

\subsection{Reconstruction of Resurfacing Hip Arthroplasty}

This study presents eight femur models to be compared during the sideways fall accident. The models consist of the intact femur, femur implanted with straight implant placement, varus implant placement, and valgus implant placement. There are three models developed in the varus and valgus placement zone with an increment of six-degree orientation between each placement. The implant placement was based on the cases reported by medical institutions, where the average values of $6^{\circ}-18^{\circ}$ were obtained. Figure 2 shows the implanted femur models developed in this study. 


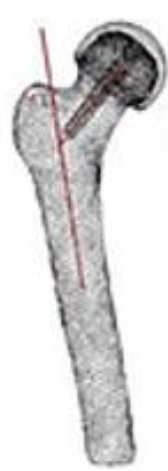

(a)

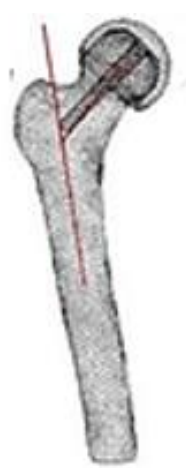

(b)

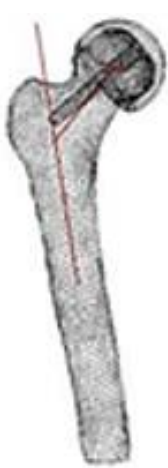

(c)

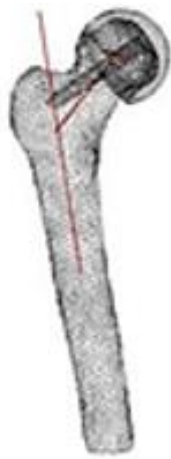

(d)

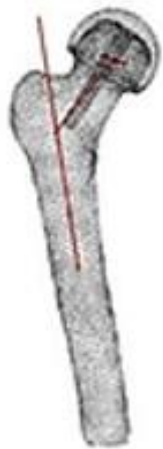

(e)

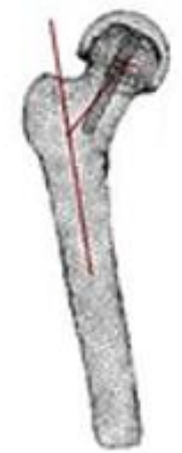

(f)

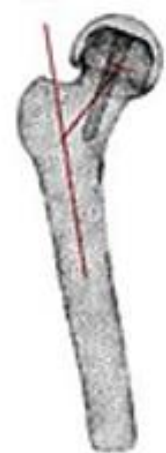

(g)

Figure 2 Femur models with RHA implant oriented in: (a) straight placement, $0^{\circ}$; (b) $+6^{\circ}$ varus; (c) $+12^{\circ}$ varus; (d) $+18^{\circ}$ varus; (e) $-6^{\circ}$ valgus; (f) $-12^{\circ}$ valgus; and (g) $-18^{\circ}$ valgus

\subsection{Loading and Boundary Conditions}

The loading and boundary conditions for the sideways fall were applied based on the study conducted by Bessho et al. (2009). The loading and boundary conditions for the falling configuration are illustrated in Figure 3. The loading direction applied for the falling configuration was based on two criteria: $\alpha=120^{\circ}$ (with reference to the femur shaft axis in the frontal plane) and $\beta=0^{\circ}$ (with reference to the femur neck axis in the horizontal plane). The trochanteric area and distal end area of the femur were fixed for the simulation. For this sideways fall condition, the loading magnitude applied started with the body weight of the patient ( $1 \mathrm{BW}$ ), and then increased to five times the patient's body weight ( $5 \mathrm{BW}$ ). The increments of loading magnitude from 1 to $5 \mathrm{BW}$ were chosen since there is no evidence of the exact loading magnitude for sideways falls. Thus, the current study has predicted that the potential loading magnitude might increase to 5 BW loading depending on the fall type and condition (Abdullah et al., 2014). Table 3 shows the value of load applied from 1 to 5 BW.
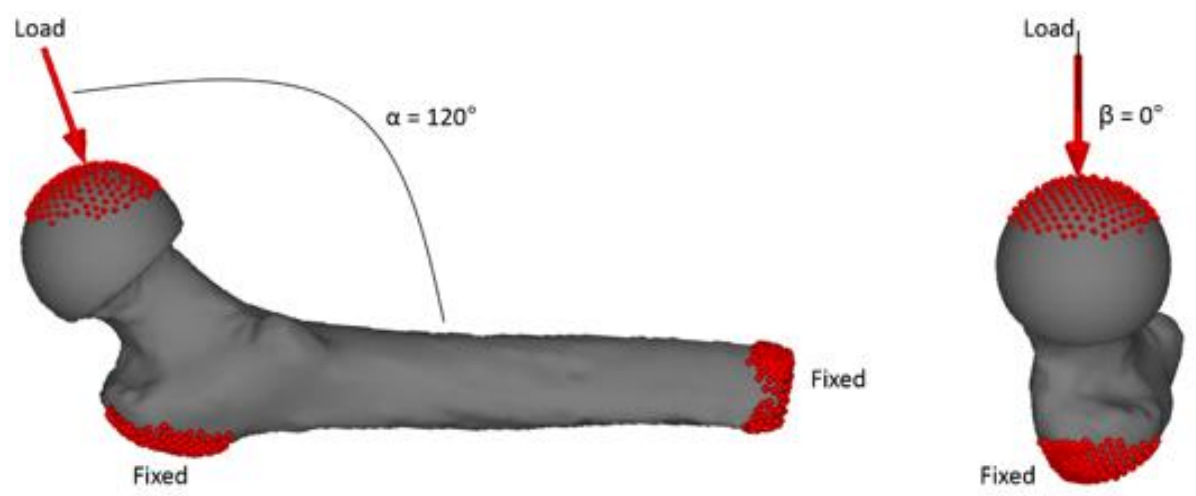

Figure 3 Loading and boundary conditions for sideway fall at different views

\subsection{Damage Formation Criterion of Elements in Predicting the Risk of Bone Fracture}

The prediction of fracture location and formation was based on the failure of elements occurring at the femur model as the load was applied to the femur. The failure of elements can be categorized into two criteria: tensile failure and compressive failure. The failure criteria of each element are described in Table 4. For tensile failure, the initiation of failure of the element was held when the maximum principal stress, $\sigma_{p}$ exceeded the 0.8 compressive yield stress, $\sigma_{r}$ which was based on findings in published experimental studies. 
Table 3 Applied load value from 1BW until 5BW

\begin{tabular}{cc}
\hline Body weight $(\mathrm{BW})$ & Contact force $(\mathrm{N})$ \\
\hline 1 & 859.36 \\
2 & 1718.71 \\
3 & 2578.07 \\
4 & 3437.42 \\
5 & 4296.78 \\
\hline
\end{tabular}

Previous experimental studies have stated that the ultimate tensile stress of cortical and cancellous bone was $76 \%$ and $79 \%$ of the compressive yield stress, respectively (Keaveny et al., 1994; Kaneko et al., 2003). For compressive failure, there was a two-stage process to reach element failure. The yield criterion of Drucker-Prager was adopted. If the Drucker-Prager equivalent stress, $\sigma_{D}$ exceeded the yield stress, the element was regarded as a yielded state (i). After that, the initiation of failure in the compressive direction happened when the minimum principal strain, $\varepsilon_{p}$ of an element was lower than -3000 microstrain in the yielded state (ii). For the case of the strain value, the value was set according to previous studies (Røhl et al., 1991; Kaneko et al., 2003) which stated that the ultimate strain value of a bone during compressive loading was within the range of - 3000 to -28000 microstrain.

Table 4 Damage formation criterion of an element

\begin{tabular}{ccc}
\hline $\begin{array}{c}\text { Failure category } \\
\text { Tensile failure }\end{array}$ & Failure initiation & Criterion \\
& $\sigma_{\mathrm{p}}>0.8 \sigma_{\mathrm{r}}$ \\
\hline \multirow{2}{*}{ Compressive failure } & (i) Transition to yielded state & $\sigma_{\mathrm{D}}>\sigma_{\mathrm{r}}$ \\
& (ii) Failure initiation & $\varepsilon_{\mathrm{p}}<-3000$ (in yielded state) \\
\hline
\end{tabular}

$\sigma_{\mathrm{p}}:$ maximum principal stress

$\sigma_{\mathrm{D}}:$ Drucker-Prager equivalent stress

$\sigma_{\mathrm{r}}:$ yield stress

$\varepsilon_{\mathrm{p}}:$ minimum principal strain

\section{Results and Discussion}

The risk of bone fracture for all femurs was predicted by using the biomechanical software Mechanical Finder, which applied the damage formation criteria as in the literature.

\subsection{Validation of the Inhomogeneous Femoral Bone Model}

The inhomogeneous bone model in this study has been validated in a previous experimental study (Simões et al., 2000), which investigated the pattern of strain distribution within the lateral and medial regions of a synthetic femur. In this study, the strain distribution was validated by using the intact finite element (FE) femur model. A simulation analysis was conducted by referring to the author's second load case. The loads applied to the joint reaction force and abductor muscle force in this results section were $700 \mathrm{~N}$ and $300 \mathrm{~N}$, respectively, with a fixed boundary at the distal end of the femur, which is similar to the experiment. Figure 4 shows the comparison of the strain distribution pattern obtained from our FE model with the strain distribution pattern of the synthetic femur, as in the experimental study.

The strain pattern produced by the FE model was similar to that reported by Simões et al. (2000); however, the differences in strain values between the studies might be due to the difference in bone density between human and synthetic femurs. The mechanical 
behavior of a synthetic femur might be different from the human femur, which is related to its cortical and cancellous bone properties (Nicayenzi et al., 2011), thus affecting the strain values. Nonetheless, the femur model used in this FE study was verified and sufficient to conduct computational analysis.
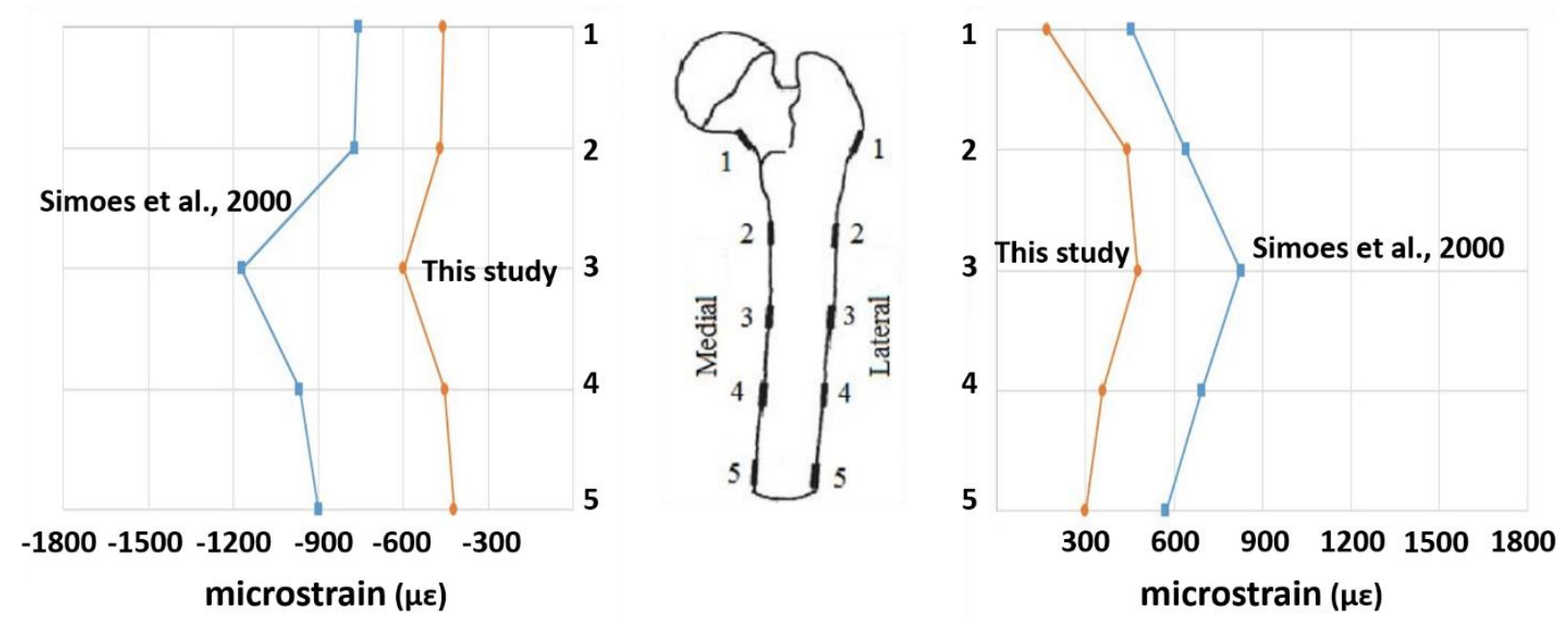

Figure 4 Comparison of strain distribution within the medial and lateral aspects of the femur

\subsection{Failure of Elements during Sideway Fall Condition}

The simulation of the sideways fall accident in this study was done by applying several load values. The load was applied from one to five times the patient's body weight in all femur models (intact and implanted) to identify the fracture strength of the femur during the sideways fall. The fracture risks were evaluated by the damage formation of the failure elements where, to the authors' knowledge, this approach has not yet been applied to RHA models with implants oriented in valgus and varus placement.

Figure 5 shows the changes of failure elements by body weight increments. The comparison was done by obtaining the mean number of element failures for each group of placements. The risk of bone fracture was predicted to be higher for the femur implanted with varus placement, followed by straight placement and valgus placement. The intact femur was found to have the lowest number of failure elements from 1 BW to 5 BW, providing evidence that the fracture strength of the femur was reduced by the presence of the RHA implant. The changes in failure elements were predicted to increase exponentially as a higher load was applied.

The significant difference in element failures between the intact and implanted femurs can be seen as the $4 \mathrm{BW}$ load was applied. The mean number of element failures obtained from the implanted femurs exceeded 50 elements, while the intact femur was still below that value. Thus, it is understood that the risk of bone fracture is higher for the implanted femur when the femur is exposed to a higher loading magnitude.

In addition, there is a huge difference shown by the implanted femur compared to the intact femur after loading with $5 \mathrm{BW}$. The number of failure elements obtained from the intact femur is 35, while 295 elements failed for the varus placement, 250 elements for the straight placement, and 165 elements for the valgus placement. The tendency of bone fracture increased up to $371 \%$ for the implanted femurs in this circumstance, which supports the previous statement. 


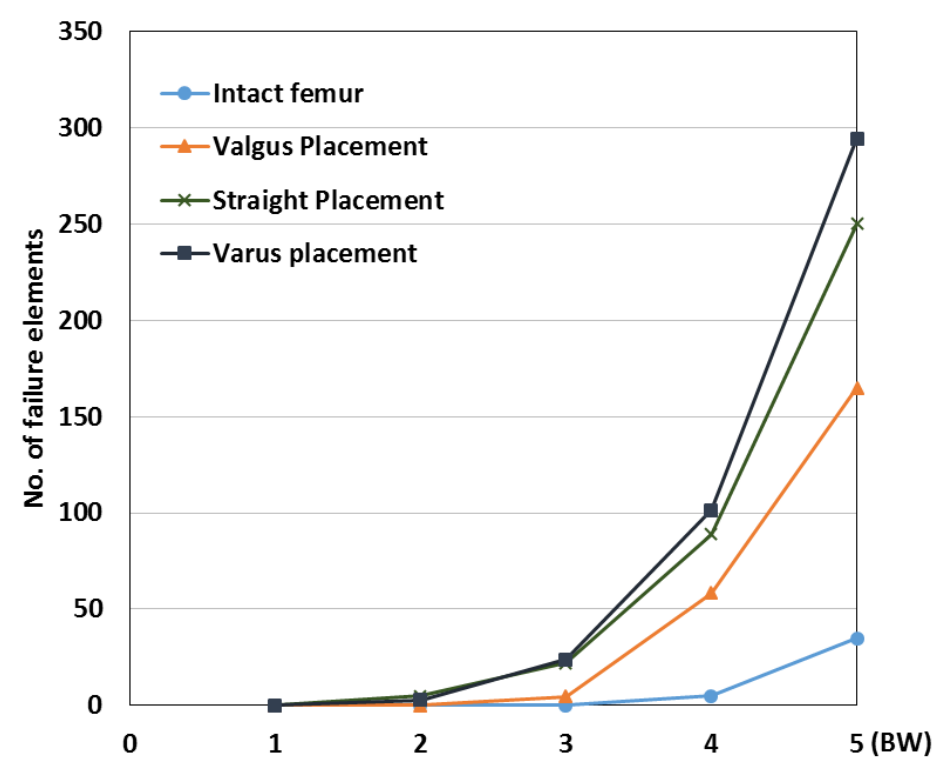

Figure 5 Number of failure elements with the increment of bodyweight during sideway fall

\subsection{Fracture Formation of the Femoral Bone during Sideway Fall}

To identify the predicted fracture formation and location during the sideways fall, a comparison was made between the intact femur and the implanted femur within the valgus $-18^{\circ}$, straight placement, and varus $+18^{\circ}$ placement in the $5 \mathrm{BW}$ load condition. Although the highest number of failure elements was obtained at the femur implanted with varus $+6^{\circ}$ (Figure 6), the increase percentage between varus $+6^{\circ}$ and valgus $-6^{\circ}$ was lower than the femur implanted with varus $+18^{\circ}$ and valgus $-18^{\circ}$. It was found that the highest difference of failure elements was between the varus $+18^{\circ}$ and valgus $-18^{\circ}$ with an increase of $205 \%$.

The findings in Figure 7 show that the fracture formations occurred in all models, even though the location varied between them. Bone fracture occurred in the area exposed to the load due to high-stress concentrations. The element that fractured in tensile failure is represented by the cracked solids (white), while for compressive failure, it is represented by the crushed (red) and plastic (yellow) solids.

For the intact femur (Figure 7a), fracture formation is predicted to be located at the neck area of the femur. The fracture location for the intact femur obtained in this study was comparable to the findings by Bessho et al. (2009) and Abdullah et al. (2014). Also, the type of element failure was found to be only in the compressive direction. The absence of the RHA implant might be the reason the element failed in such a direction since the femur was not affected by bending effects of the implant pin after loading.

Interestingly, the type of element failure produced by the femur implanted with valgus $-18^{\circ}$ placement (Figure $7 \mathrm{~b}$ ) was similar to the intact femur. The element failures were dominated by the compressive failure direction even after implantation with the RHA prosthesis. It is believed that the implant pin might contribute to the failure in the tensile direction, which is due to the bending effects of the pin; however, its existence is insignificant for the femur implanted with valgus $-18^{\circ}$ placement. In addition to this finding, a clear comparison can be seen for the straight and varus placements (Figures 7c and 7d), where both femurs have fractured in the tensile failure direction at the bone area within the implant pin.

However, in the case of the implanted femur (varus, straight, and valgus), fracture formation was found to be concentrated at the trochanter region of the femur. This might 
be due to the high compressive stress transferred by the metallic implant to the trochanteric area of the femur during the falling condition. The most obvious fracture formation is observed at the femur with varus placement, which indicates that the RHA implant placement in this zone is most vulnerable to fracture risk.

According to Fraile Gamarra et al. (2019), the valgus placement of the RHA implant might have a preventive effect against fracture, which is demonstrated by the results in this study. On the other hand, the femur implanted in varus placement was demonstrated to have the highest risk of failure. Therefore, we suggest that the varus placement of the RHA implant should be avoided whenever possible, especially in clinical practice. This is in line with recent studies (Sershon et al., 2016) which emphasized the importance of careful preparation of the resurfacing hip implant by the surgeon.

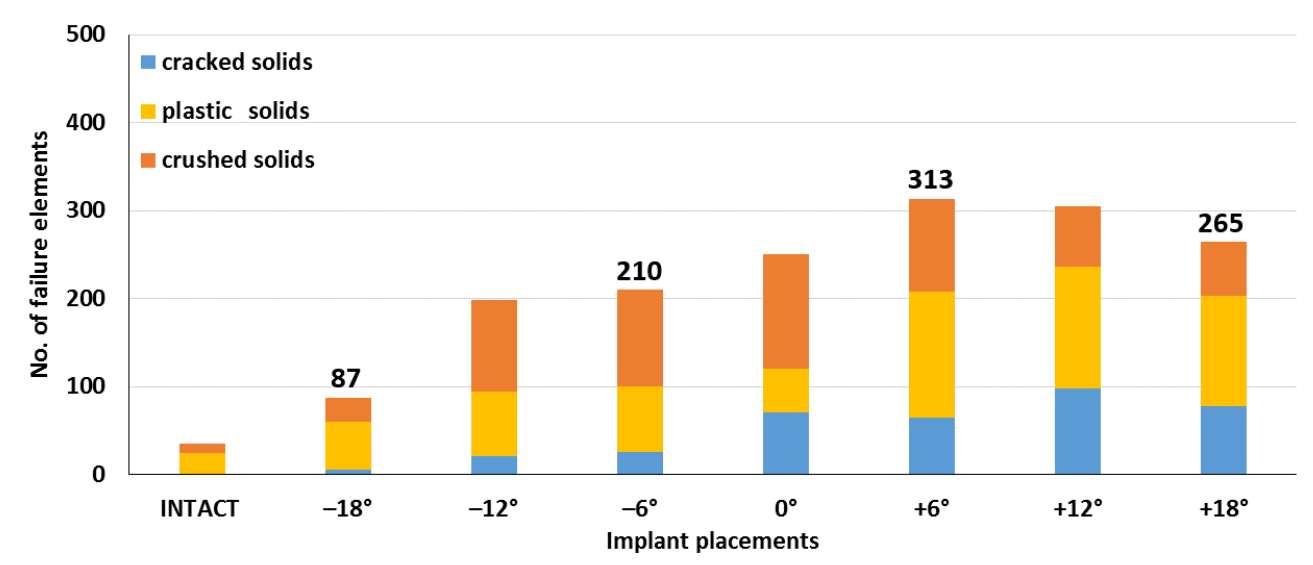

Figure 6 Number of failure elements between all models in 5BW loaded

(a)
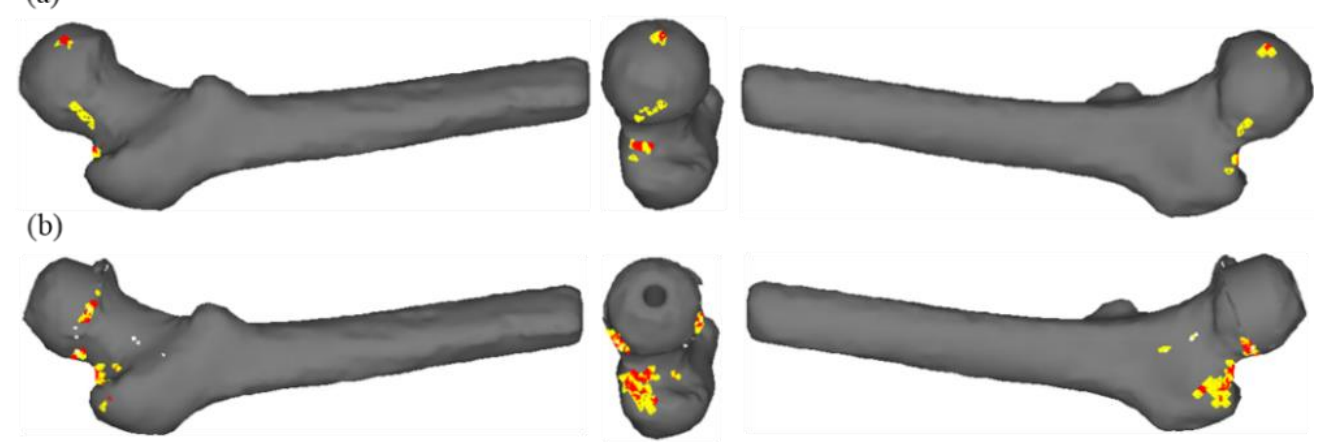

(1)
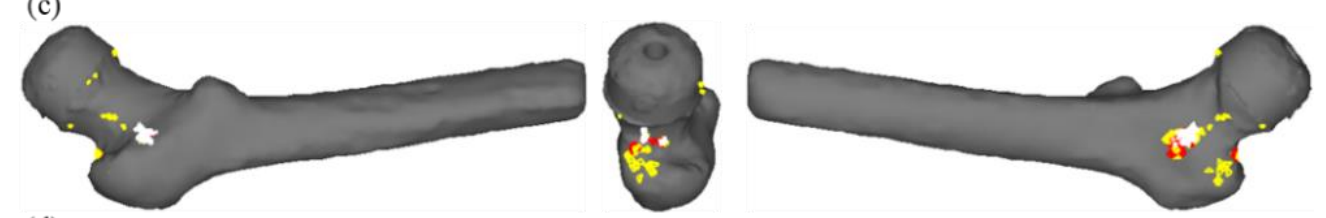

(d)
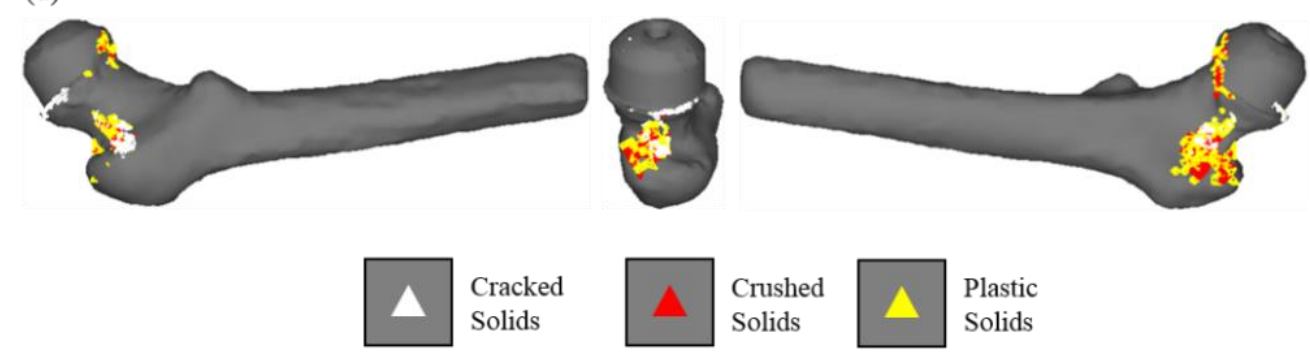

Crushed Solids

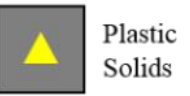

Figure 7 Comparison of fracture formation between: (a) intact femur; (b) valgus $-18^{\circ}$; (c) straight; $0^{\circ}$; and (d) varus $+18^{\circ}$ with 5BW applied load from posterior-superior-anterior view 


\section{Conclusions}

The present study demonstrates the risk of femoral bone fracture in the case of a sideways fall accidents. As hip arthroplasty is needed for late-stage hip OA patients, the placement of the implant has a huge impact on the survivability of the femoral bone. Although all femurs are predicted to fracture at the highest load applied ( $5 \mathrm{BW}$ ), the femur implanted in valgus placement shows the lowest fracture formation when compared to the varus and straight placements. The result shows that the valgus placement of the RHA implant might have a preventive effect against fracture where the possibility of fracture is reduced by $44 \%$ and $34 \%$ compared to the varus and straight placement conditions. The increase of failure elements as the implant is oriented from valgus to varus suggests that the risk of bone fracture is higher when the implant is positioned in the varus placement zone.

\section{Acknowledgements}

This research was supported by Universiti Teknologi MARA, UiTM under Grant No. 600- IRMI/PERDANA 5/3 BESTARI (103/2018). We thank and acknowledge the Ministry of Education, Malaysia, and our colleagues from the Faculty of Medicine, UiTM, who provided insight and expertise that greatly assisted the research.

\section{References}

Abdullah, A.H., Todo, M., Nakashima, Y., Iwamoto, Y., 2014. Risk of Femoral Bone Fractures in Hip Arthroplasties during Sideway Falls. International Journal of Applied Physics and Mathematics, Volume 4(4), pp. 286-289

Abdullah, A.H., Todo, M., Nakashima, Y., 2017. Prediction of Damage Formation in Hip Arthroplasties by Finite Element Analysis using Computed Tomography Images. Medical Engineering and Physics, Volume 44, pp. 8-15

Amanatullah, D.F., Cheung, Y., Di Cesare, P.E., 2010. Hip Resurfacing Arthroplasty: A Review of the Evidence for Surgical Technique, Outcome, and Complications. Orthopedic Clinics of North America, Volume 41(2), pp. 263-272

Beaulieu, M.L., Lamontagne, M., Beaulé, P.E., 2010. Lower Limb Biomechanics during Gait Do Not Return to Normal Following Total Hip Arthroplasty. Gait and Posture, Volume 32(2), pp. 269-273

Bessho, M., Ohnishi, I., Matsumoto, T., Ohashi, S., Matsuyama, J., Tobita, K., Kaneko, M., Nakamura, K., 2009. Prediction of Proximal Femur Strength using a CT-based Nonlinear Finite Element Method: Differences in Predicted Fracture Load and Site with Changing Load and Boundary Conditions. Bone, Volume 45(2), pp. 226-231

Brunner, L.C., Eshilian-Oates, L., Kuo, T.Y., 2003. Hip Fractures in Adults. American Family Physician, Volume 67(3), pp. 537-542

Elfani, M., Putra, N.K., 2013. Biomedical Engineering and Its Potential for Employment in Indonesia. International Journal of Technology, Volume 4(1), pp. 34-44

Fraile Gamarra, I., Jiménez Viseu Pinheiro, J.F., Cano Gala, C., Blanco Blanco, J.F., 2019. Birmingham Mid-head Resection Periprosthetic Fractures: Case Report. International Journal of Surgery Case Reports, Volume 64, pp. 174-176

Freeman, M.A., 1978. Some Anatomical and Mechanical Considerations Relevant to the Surface Replacement of the Femoral Head. Clinical Orthopaedics and Related Research, Volume 134, pp. 19-24 
Freeman, M.A.R., Cameron, H.U., Brown, G.C., 1978. Cemented Double Cup Arthroplasty of the Hip: A Five Year Experience with the ICLH Prosthesis. Clinical Orthopaedics and Related Research, No. 134, pp. 45-52

Goshulak, P., Samiezadeh, S., Aziz, M.S.R., Bougherara, H., Zdero, R., Schemitsch, E.H., 2016. The Biomechanical Effect of Anteversion and Modular Neck Offset on Stress Shielding for Short-Stem versus Conventional Long-Stem Hip Implants. Medical Engineering and Physics, Volume 38(3), pp. 232-240

Isaac, G.H., Siebel, T., Schmalzried, T.P., Cobb, A.G., O’Sullivan, T., Oakeshott, R.D., Flett, M., Vail, T.P., 2006. Development Rationale for an Articular Surface Replacement: A Science-based Evolution. In: Proceedings of the Institution of Mechanical Engineers, Part H: Journal of Engineering in Medicine, Volume 220(2), pp. 253-268

Kaneko, T.S., Pejcic, M.R., Tehranzadeh, J., Keyak, J.H., 2003. Relationships between Material Properties and CT Scan Data of Cortical Bone with and without Metastatic Lesions. Medical Engineering and Physics, Volume 25(6), pp. 445-454

Keaveny, T.M., Wachtel, E.F., Ford, C.M., Hayes, W.C., 1994. Differences between the Tensile and Compressive Strengths of Bovine Tibial Trabecular Bone Depend on Modulus. Journal of Biomechanics, Volume 27(9), pp. 1137-1146

Keyak, J.H., Rossi, S.A., Jones, K.A., Skinner, H.B., 1997. Prediction of Femoral Fracture Load using Automated Finite Element Modeling. Journal of Biomechanics, Volume 31(2), pp. 125-133

Keyak, J.H., Skinner, H.B., Fleming, J.A., 2001. Effect of Force Direction on Femoral Fracture Load for Two Types of Loading Conditions. Journal of Orthopaedic Research, Volume 19(4), pp. 539-544

Kim, S.C., Jung, H.M., 2013. A Study on Performance of Low-dose Medical Radiation Shielding Fiber (RSF) in CT Scans. International Journal of Technology, Volume 4(2), pp. 178-187

Kurdi, O., Rahman, R.A., 2010. Finite Element Analysis of Road Roughness Effect on Stress Distribution of Heavy Duty Truck Chassis. International Journal of Technology, Volume 1(1), pp. 57-64

Lavigne, M., Vendittoli, P.A., Nantel, J., 2008. Gait Analysis in Three Types of Hip Replacement. In: The $75^{\text {th }}$ Annual Proceedings of American Academy of Orthopaedic Surgeons, Symposium, p. 431

Mont, M.A., Seyler, T.M., Ulrich, S.D., Beaule, P.E., Boyd, H.S., Grecula, M.J., Goldberg, V.M., Kennedy, W.R., Marker, D.R., Schmalzried, T.P., Sparling, E.A., Vail, T.P., Amstutz, H.C., 2007. Effect of Changing Indications and Techniques on Total Hip Resurfacing. Clinical Orthopaedics and Related Research, Volume 465, pp. 63-70

Izmin, N.A.N., Hazwani, F., Todo, M., Abdullah, A.H., 2020. Development of Inhomogeneous Femoral Bone Model for CT-based Finite Element Analysis. Journal of Scientific and Engineering Research, Volume 7(6), pp. 98-103

Nicayenzi, B., Shah, S., Schemitsch, E.H., Bougherara, H., Zdero, R., 2011. The Biomechanical Effect of Changes in Cancellous Bone Density on Synthetic Femur Behaviour. In: Proceedings of the Institution of Mechanical Engineers, Part H: Journal of Engineering in Medicine, Volume 225(11), pp. 1050-1060

Quesada, M.J., Marker, D.R., Mont, M.A., 2008. Metal-on-Metal Hip Resurfacing. Advantages and Disadvantages. Journal of Arthroplasty, Volume 23, pp. 69-73

Røhl, L., Larsen, E., Linde, F., Odgaard, A., Jørgensen, J., 1991. Tensile and Compressive Properties of Cancellous Bone. Journal of Biomechanics, Volume 24(12), pp. 1143-1149 
Sershon, R., Balkissoon, R., Valle, C.J.D., 2016. Current Indications for Hip Resurfacing Arthroplasty in 2016. Current Reviews in Musculoskeletal Medicine, Volume 9(1), pp. 84-92

Shimmin, A.J., Back, D., 2005. Femoral Neck Fractures Following Birmingham Hip Resurfacing: A National Review of 50 Cases. Journal of Bone and Joint Surgery - British Volume, Volume 87(4), pp. 463-464

Shimmin, A.J., Bennell, K., Wrigley, T., 2008. Gait Analysis Comparison of the Functional Outcome of Hip Resurfacing and Total Hip Replacement. In: The 75 th Annual Proceedings of American Academy of Orthopaedic Surgeons, Symposium, p. 382

Simões, J.A., Vaz, M.A., Blatcher, S., Taylor, M., 2000. Influence of Head Constraint and Muscle Forces on the Strain Distribution within the Intact Femur. Medical Engineering and Physics, Volume 22(7), pp. 453-459

Tawara, D., Sakamoto, J., Murakami, H., Kawahara, N., Oda, J., Tomita, K., 2010. Mechanical Therapeutic Effects in Osteoporotic L1-Vertebrae Evaluated by Nonlinear PatientSpecific Finite Element Analysis. Journal of Biomechanical Science and Engineering, Volume 5(5), pp. 499-514

Todo, M., 2018. Biomechanical Analysis of Hip Joint Arthroplasties using CT-Image Based Finite Element Method. Journal of Surgery and Research, Volume 01, pp. 34-41

Vail, T.P., Mina, C.A., Yergler, J.D., Pietrobon, R., 2006. Metal-On-Metal Hip Resurfacing Compares Favorably with THA at 2 Years Follow up. Clinical Orthopaedics and Related Research, Volume 453, pp. 123-131

Wagner, P., Olsson, H., Ranstam, J., Robertsson, O., Zheng, M.H., Lidgren, L., 2012. Metal-OnMetal Joint Bearings and Hematopoetic Malignancy: A Review. Acta Orthopaedica, Volume 83(6), pp. 553-558 